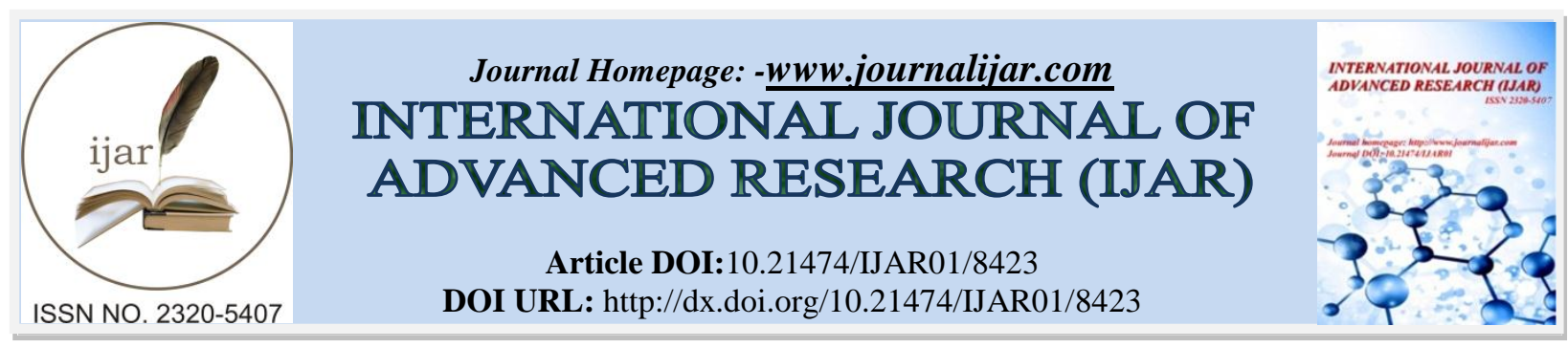

RESEARCH ARTICLE

\title{
INCREASED FASTING PLASMA GLUCOSE LEVEL IN YOUNG ADULTS WITH HIGH BMI AS PREDICTOR OF DIABETES MELLITUS 2.
}

AnkitaJuyal and Joshil Kumar Behera.

\section{Manuscript Info}

Manuscript History

Received: 16 November 2018

Final Accepted: 18 December 2018

Published: January 2019
Abstract

Copy Right, IJAR, 2018,. All rights reserved.

\section{Introduction:-}

The Term diabetes mellitus describes a metabolic disorder of multiple etiologies typified by chronic hyperglycemia $\&$ chaos of carbohydrate, fat \& protein metabolism resulting from defects in insulin secretion, insulin action, or both. Recent estimates indicate $\approx 171$ million people in the world with diabetes in year $2000 \&$ this is projected to increase to 366 million by 2030(1). Obesity is one of the most important modifiable risk factors in pathogenesis of type 2 diabetes. Global epidemic obesity "GLOBESITY"- is rapidly becoming a major public health problem in the world and is on the rise (2).

The condition of 'diabesity' is a compartively newer terminology associated with the interrelationship between diabetes and obesity firstly coined by Sims et al. in 1973. The health impact of diabesity is substantial to include long-term diabetic complications, reduction in health-related functioning, reduction of quality of life and reduced overall life expectancy. Long-term complications include myocardial infarction, cerebrovascular stroke and endstage renal disease. It is thus urgent to take steps including screening, prevention and early management in an attempt to control this evolving epidemic of diabesity (3).

Onset of type 2 diabetes, the predominant form of diabetes, occurs most commonly in adulthood and is characterised by reduced insulin production and/or reduced insulin responsiveness ; in contrast, type 1 diabetes, accounting for approximately $5-10 \%$ of all diabetes cases, is characterised by autoimmune destruction of insulin-producing cells and onset occurs most commonly in childhood. Type 2 diabetes is potentially preventable given the role of lifestyle factors such as obesity and lack of physical activity in its pathogenesis (4).

Obesity marker-Body Mass $\underset{2}{2} \underset{2}{\operatorname{2}}$ (BMI) (1)

BMI = Weight $(\mathrm{Kg}) /$ Height $(\mathrm{m})$

BMI values: Age-independent and same for both the sexes.

\begin{tabular}{|l|l|}
\hline WHO Criteria & BMI $(\mathrm{kg} / \mathrm{m} 2)$ \\
\hline Normal range & $18.5-24.9$ \\
\hline Overweight & $25.0-29.9$ \\
\hline \hline Obese & $\geq 30.0$ \\
\hline Obese class I & $30.0-34.9$ \\
\hline Obese class II & $35.0-39.9$ \\
\hline Obese class III & $\geq 40.00$ \\
\hline
\end{tabular}




\begin{tabular}{|l|c|}
\hline Condition & FPG (According to WHO) \\
\hline Normal & Less than $100 \mathrm{mg} / \mathrm{dL}(\mathrm{mg}$ per $\mathrm{dl})$ \\
\hline Prediabetes & $100 \mathrm{mg} / \mathrm{dL}-125 \mathrm{mg} / \mathrm{dL}$ \\
\hline Diabetes & $126 \mathrm{mg} / \mathrm{dL}$ or greater on two or more tests \\
\hline
\end{tabular}

\begin{tabular}{|l|l|}
\hline Condition & OGTT at 2 hours \\
\hline Normal & Less than $140 \mathrm{mg} / \mathrm{dL}$ \\
\hline Prediabetes & $140 \mathrm{mg} / \mathrm{dL}$ to $199 \mathrm{mg} / \mathrm{dL}$ \\
\hline Diabetes & Greater than $200 \mathrm{mg} / \mathrm{dL}$ \\
\hline
\end{tabular}

\section{Materials and Method:-}

The study was carried out on 100 normal healthy subjects aged 18-20 years were informed and consented to participate in the study.

They were divided into 3 groups according to their BMI \& WHO criteria (1):

Gp A: Normal weight

Gp B: Overweight

Gp C: Obese

Those with a known history of diabetes, hypertension, and other related endocrine disorders, or those on medication that might influence plasma glucose were excluded from the study.

After an overnight fast for 12 to 14 hours their fasting blood glucose (FBG) levels were measured by Glucometer (SD check gold strip monitoring system).

Weight was recorded to nearest $0.5 \mathrm{~kg}$ a portable weighing scale and height was recorded to nearest $0.5 \mathrm{~cm}$ in standard standing position without shoes by using a tape meter, while keeping shoulders in erect position and Body Mass Index $(\mathrm{kg} / \mathrm{m} 2)$ determined. Their blood pressure (BP) was taken using a mercury sphygmomanometer.A fasting blood sugar level above $126 \mathrm{mg} / \mathrm{dl}$ was confirmed as diabetic.

Descriptive statistics of variables were determined. The differences of mean+SD of variables between sexes were compared using Student's t-test. Correlations between plasma glucose and BMI, and glucose and age were done using Pearson's correlation coefficient. A graph of glucose against age was plotted to see if plasma glucose increased with age. Also a graph of glucose against BMI was plotted to demonstrate changes in plasma glucose with increasing BMI. P values of $\leq 0.05$ were considered significant.

Observation and Results:-

\begin{tabular}{|l|l|l|}
\hline Groups & BMI Kg/m $\mathrm{m}^{2}$ & FBG $\mathrm{mg} / \mathrm{dl}$ \\
\hline A & $20.3 \pm 2.1$ & $94.4 \pm 2.7$ \\
\hline B & $27.3 \pm 1.9$ & $98.4 \pm 1.6$ \\
\hline C & $31.9 \pm 1.3$ & $108.4 \pm 5.3$ \\
\hline Total & $26.5 \pm 2.0$ & $100.4 \pm 3.6$ \\
\hline
\end{tabular}




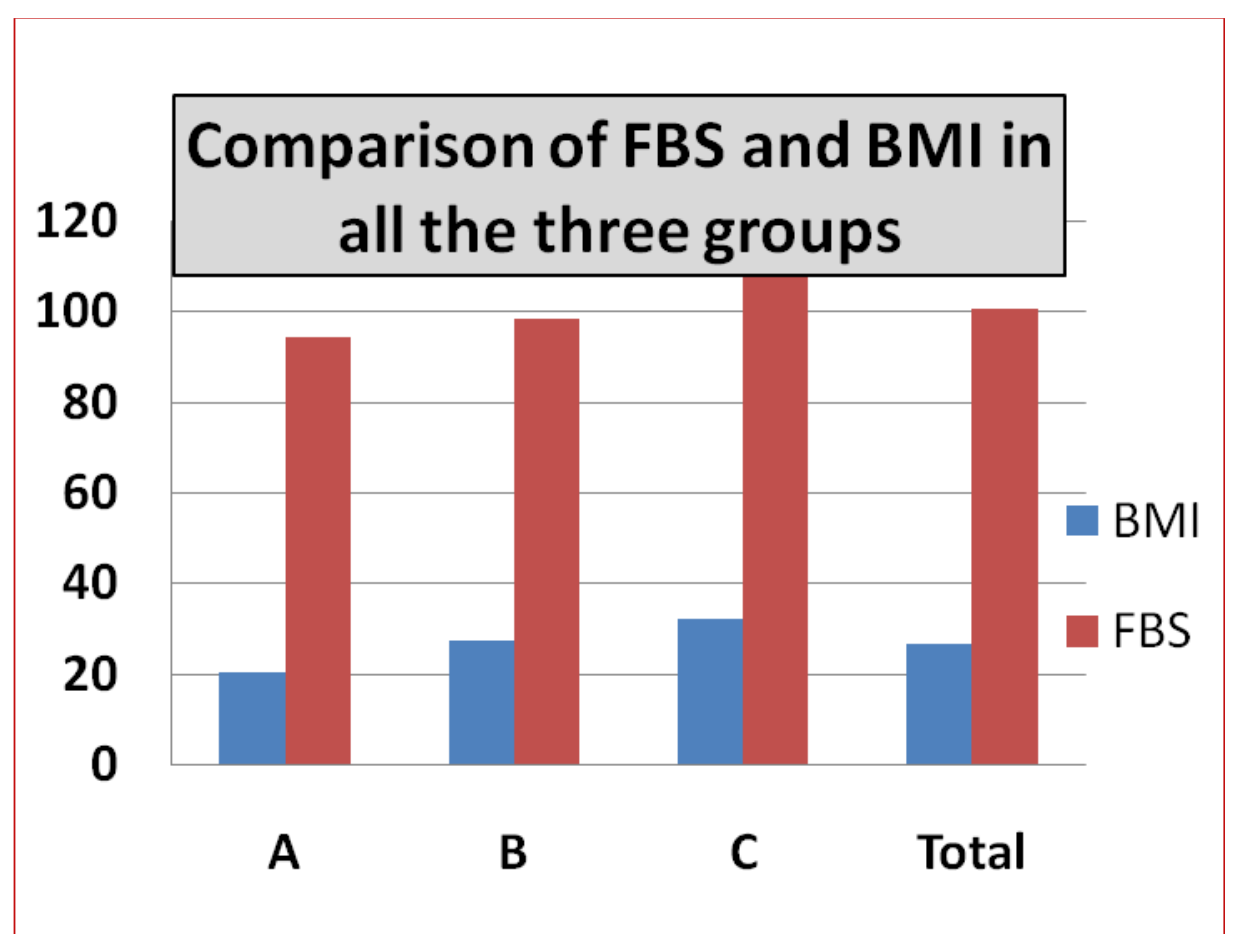

1. The mean FBS (FPG) of the study population was $100.4 \pm 3.6 \mathrm{mg} / \mathrm{dl}$ and the mean BMI was $26.5 \pm 2.0$.

2. On comparing the values, FBG was highest in Group C (FBG $108.4 \pm 5.3 \mathrm{mg} / \mathrm{dl}$; BMI $31.9 \pm 1.3$ ), followed by Group B (FBG: $98.4 \pm 1.6$; BMI $27.3 \pm 1.9$ ) and then Group A (FBG: $94.4 \pm 2.7$; BMI $20.3 \pm 2.1$ ).

3. However the difference was statistically insignificant ( $p$ value $>0.05$ ).

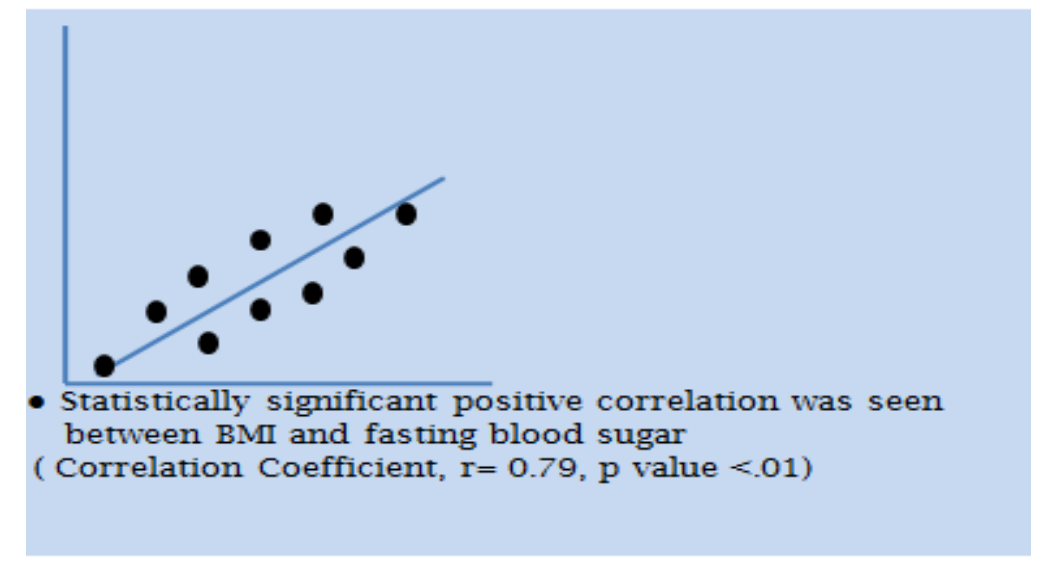

\section{Discussion:-}

It has been observed that Indians are highly susceptible to diabetes cardiovascular risk even with only modest overweight, central obesity and decrease in physical activity (5). Obesity is a growing global Public Health concern affecting people of all age groups and socioeconomic status (6). Lower and middle income countries (LMIC) are also experiencing a marked increase in overweight and obesity $(7,8)$.

In the present study, Obese subjects showed prediabetic level of blood glucose in comparison to overweight and normal weight individiuals means BMI showed a positive correlation with FBS (Pearson's correlation coefficient $\mathrm{r}=0.79$, $\mathrm{p}$ value <.01). A positive correlation amid BMI and blood sugar was also found in other studies $(9,10)$. These findings are in accordance with other studies, which showed that overweight and obesity are consistent parameters associated with cardiovascular risk in most populations (11).

The limitations of the present study are obesity is assessed only by BMI. This isolated use of BMI runs the risk of missing those who, in spite of having a normal BMI, are at risk of metabolic disorders later on. Ideally other 
measures such as DEXA scans would more accurately measure the body composition but even incorporating other more convenient low cost measures like skin folds or waist circumference would be valuable in assessing excess body fat in young individuals with normal BMI, given the metabolic changes are observed early in the life course. The other limiting factors are like physical activities, and insulin level was not measured among subjects and also the small sample size (12).

\section{Conclusions:-}

Young adults are prone to overweight and obesity during the transition from adolescence to adult in developing countries as much as in developed countries. Using other convenient low cost measures to assess body fat in addition to BMI to measure obesity might be useful to identify obesity in young adults, which is especially important to counter the risk of metabolic imbalances like diabetes mellitus in later life.

\section{References:-}

1. World Health Organization: Definition, Diagnosis and Classification of Diabetes Mellitus and its Complications: Report of a WHO Consultation. Part 1: Diagnosis and Classification of Diabetes Mellitus. Geneva, World.

2. Health Org., 1999). (2) WHO Global InfoBase team. Surveillance of chronic diseases and risk factors: Country level data and comparable estimates. Geneva: World Health Organisation, 2005.

3. Gill, T. 2006. "Epidemiology and Health Impact of Obesity: An Asian Perspective." Asia Pacific Journal of Clinical Nutrition, 15: 3-14.

4. Sims EAH, Danforth E, Horton ES, Bray GA, Glennon JA, Salans LB: Endocrine and metabolic effects of experimental obesity in man. Recent ProgHorm Res 1973, 29:457-96

5. Sanchez M, Panahi S, Tremblay A: Childhood Obesity: A Role for Gut Microbiota? Int Journal of Env Res and Pub Hlth 2014, 12:162-75.

6. Singh, R.B. and M.A. Niaz, Coronary risk factors in Indians. Lancet. 1995; 346:778-779.

7. WHO Expert Consultation. Appropriate body-mass index in Asian populations and its implications for policy and intervention strategies, Lancet. 2004; 363: 157-63.

8. Adamu GB, Geoffrey CO, Bala GS, Ibrahim SA, Sani SH, Tambaya MA. Relationship between random blood sugar and body mass index in anAfrican population. Int J Diabetes\&Metabolism 2006; 14: 144-5.

9. Jhanghorbani M, Hedley AJ, Jones RB, Gilmour WH. Is the association between glucose leveland "all causes" and cardiovascular mortality risk dependent on body mass index? Med. J.Islamic Republic Iran 1992; 6:205-12.

10. Singh, R.B. and M.A. Niaz, Coronary risk factors in Indians. Lancet. 1995; 346:778-779. 7. Nelson DL and Cox MM: Lehninger Principles of Biochemistry. 4th (ed), W.H Freeman and Company, New York. 2005

11. Saiem Al-Dahr, M.H. and E.H. Jiffri, Increased adipose tissue expression of tumor necrosis factor- alpha and insulin resistance in obese subjects with type II diabetes. World J. Medical Sci. 2010; 5:30-5.

12. Kragelund C, Hassager C, Hildebrandt P, Torp-Pedersen C, Kober L. Impact of obesity on long-term prognosis following acute myocardial infarction. Int J Cardiol. 2005; 98:123-31. 